\title{
Toxicity of OTC to Ipomoea aquatica Forsk. and to microorganisms in a long-term sewage-irrigated farmland soil
}

\author{
Tingting $\mathrm{Ma}^{1,2} \cdot$ Li'ke Chen $^{1,3} \cdot$ Longhua $\mathrm{Wu}^{1} \cdot$ Peter Christie $^{1} \cdot$ Yongming Luo $^{4}$
}

Received: 2 November 2015 / Accepted: 4 April 2016 /Published online: 16 April 2016

(C) Springer-Verlag Berlin Heidelberg 2016

\begin{abstract}
Water spinach (Ipomoea aquatic Forsk.) was selected to investigate the effects of oxytetracycline (OTC) on the toxicity of soil contaminated by long-term sewage irrigation. After acute toxicity test in petri dish at nine different OTC-spiked levels for $48 \mathrm{~h}$, the germination rate was found to be generally inhibited in all treatments treated with OTC but the root elongation and activities of several antioxidant enzymes, superoxide dismutase (SOD), peroxidase (POD) and catalase (CAT) were either forward or backward stimulated to varying extent. During a 60 -day sub-chronic toxicity test by means of a pot experiment, activities of SOD, POD and CAT in both the leaf and root tissue at $25 \mathrm{mg}$ OTC per kg soil (dry weight) and in root tissue at $1 \mathrm{mg}$ OTC per kg soil (dry weight) were significantly different than those in other treatments, which also indicated the higher sensitivity of the root. The foliar photosynthetic rate, stomatal conductance and transpiration rate were all gradually inhibited in spite of elevated water use efficiency under the pressure of the different OTC concentrations, which were highly significant different at
\end{abstract}

Responsible editor: Henner Hollert

Longhua $\mathrm{Wu}$

lhwu@issas.ac.cn

1 Key Laboratory of Soil Environment and Pollution Remediation, Institute of Soil Science, Chinese Academy of Sciences, No. 71, East Beijing Road, Nanjing 210008, China

2 Institute of Hanjiang, Hubei University of Arts and Science, Xiangyang 441053, China

3 Shanghai Research Institute of Chemical Industry, Shanghai 200062, China

4 Key Laboratory of Coastal Zone Environmental Processes, Yantai Institute of Coastal Zone Research, Chinese Academy of Sciences, Yantai 264003, China
$10 \mathrm{mg}$ OTC per kg soil (dry weight). Indices of soil microbial diversity at $4 \mathrm{mg}$ OTC $\mathrm{kg}^{-1}$ soil were significantly different from those of the control, indicating the potential adverse effects of OTC to soil microorganisms. The results suggest that the introduction of OTC could damage both plants and soil microorganisms, and during sub-chronic incubation, the sensitivity of different indices generally followed the order of root tissue antioxidant enzyme activities, soil microbial diversity indices, leaf photosynthesis-related index and leaf tissue enzyme antioxidant activities. In addition, the application of livestock and poultry manure containing pollutants like OTC in farmland soil, especially if the soil has been contaminated before, should be taken more seriously in the context of the current pursuit of increased agricultural production.

Keywords Soil contamination - Oxytetracycline · Phytotoxicity $\cdot$ Biolog $\cdot$ Transmission electron microscopy

\section{Introduction}

Antibiotics are widely applied in the therapy of microbial infectious diseases of humans, livestock and poultry or as growth promoters in amounts far exceeding the requisite (Boxall et al. 2004; Zhao et al. 2010). However, antibiotics are so poorly absorbed in the digestive tracts that about 50 to $80 \%$ of the dose is directly excreted through faeces and urine in the form of parent compounds (Sarmah et al. 2006). As a consequence, antibiotic compounds are indirectly released into the environment with the application of manures and sewage sludge as fertilizers or by irrigation with recycled wastewater containing frequently detected antibiotics, usually accompanied by varying levels of organic pollutants such as polycyclic aromatic hydrocarbons (PAHs) or heavy metals 
(Wang et al. 2014; Subramanian et al. 2015) due to the development of an agrarian economy (Martínez-Carballo et al. 2007; Radjenović et al. 2009; Leung et al. 2015; Thuy and Nguyen 2013).

Oxytetracycline (OTC) is representative of the tetracycline antibiotics and is one of the most extensively employed in animal nutrition, which occurs at high residual concentrations in agricultural soils from 100 to $1700 \mu \mathrm{g} \mathrm{kg}^{-1}$ soil (Kay et al. 2004). The application of manure containing OTC has resulted in up to 2683- and 5172- $\mu \mathrm{g} \mathrm{kg}^{-1}$ OTC concentrations in amended soils of Tianjin city and Zhejiang province, respectively (Hu et al. 2010; Li et al. 2011). Tetracycline antibiotics are the most frequently found in agricultural soils throughout the world, and the residual compounds result in a potential threat to both plants and soil organisms even at concentrations that are commonly detected in agricultural soils (Aga et al. 2005; Thiele-Bruhn and Beck 2005; Sarmah et al. 2006; Karcı and Balcıoğlu 2009; Goetsch et al. 2012). A mass of investigation on the occurrence of antibiotic resistance genes (ARGs) was derived from the selection by antibiotics in recent years, indicating the contamination of natural environments or their antagonistic effects to soil microorganisms and a latent environmental threat besides the promoted genetic toxicity to plants in the soil (Xie et al. 2011; Gao et al. 2013; Zhang et al. 2015).

Phytotoxicity of antibiotics is generally assayed using seed germination and plant growth tests, investigating the effects of different soil types, plant species and pharmaceuticals (Liu et al. 2009; Migliore et al. 2010; Farzaneh et al. 2013). OTC can significantly affect soil microbial activity and high concentrations can produce visual symptoms in plants including light green or yellow colours in the leaves of alfalfa (Boleas et al. 2005; Kong et al. 2007). Application of OTC has been shown to activate existing soil pollutants such as heavy metals in contaminated soils in previous studies in our laboratory, indicating an elevated environmental risk in soils with multiple contaminants (Chen et al. 2014). There may also be effects resulting from long-term exposure to antibiotics and their metabolites on offspring or maturation period of organisms, especially from the usually ignored effects of low toxicity and low concentration, so chronic or sub-chronic toxicity effects on plants and soil microorganisms are issues of concern (Gothwal and Shashidhar 2015; Li et al. 2015).

The objectives of the present study were to elucidate the toxicity of OTC to water spinach and soil microorganisms by means of germination test and whole grow stage incubation test; and to inquire into sensitive parameters and critical concentrations of OTC toxicity effects in soils under the condition of different added concentrations and frequencies, imitating the application of sewage water and sludge in farmland production and providing suggestions for their further use.

\section{Materials and methods}

\section{Chemicals and instruments}

OTC (97.5 \%) was obtained from Dr. Ehrenstorfer GmbH, Germany. Nitro blue tetrazolium (NBT), dipotassium phosphate $\left(\mathrm{KH}_{2} \mathrm{PO}_{4}\right)$, disodium hydrogen phosphate $\left(\mathrm{Na}_{2} \mathrm{HPO}_{4}\right)$, potassium chloride $(\mathrm{KCl})$, potassium hydroxide $(\mathrm{KOH})$, hydrogen peroxide $\left(\mathrm{H}_{2} \mathrm{O}_{2}\right)$, o-methoxyphenol, riboflavin, ethylenediaminetetraacetic acid disodium salt (EDTA-Na $a_{2}$, sodium hydroxide $(\mathrm{NaOH})$, glacial acetic acid $\left(\mathrm{CH}_{3} \mathrm{COOH}\right)$, sodium chloride $(\mathrm{NaCl})$, ethyl alcohol and acetone were all analytical reagents purchased from the National Pharmaceutical Group Chemical Reagent Co. Ltd., Shanghai or Nanjing Chemical Reagent Co. Ltd.

Assay kits A045-3 for total protein content assay, A001-1 for SOD assay, A084-1 for POD assay and A004 for CAT were purchased from Nanjing Jiancheng Bioengineering Institute, China. Biolog Eco plates ${ }^{\mathrm{TM}}$ were purchased from Biolog Company, Hayward, CA. An LI-6400XT Portable Photosynthesis System was used for the determination of photosynthetic rate, transpiration rate and other variables based on the leaf area of water spinach. A Hitachi-7650 transmission electron microscope (TEM) was used for the observation of leaf ultra-structure of water spinach in the College of Life Sciences at Nanjing Agricultural University.

\section{Soil and plant seeds}

The soil tested was collected from the top $20 \mathrm{~cm}$ of the soil profile layer in an arable area contaminated by wastewater irrigation at Zhangshi wastewater irrigation area, Shenyang city, Liaoning province, northeast China. The history of industrial wastewater irrigation has been over 40 years with a 10 year break, which resulted in the relative high heavy metal contamination background. The soil was an Alfisol according to the US Department of Agriculture classification system (USDA 2011), with $15.6 \%$ clay, $76.4 \%$ silt, $7.98 \%$ sand and $2.92 \%$ organic matter. The soil $\mathrm{pH}$ was 6.66 , and the available nitrogen, phosphorus and potassium concentrations were $1.29,2.26$ and $16.9 \mathrm{~g} \mathrm{~kg}^{-1}$, respectively (Chinese Society of Soil Agricultural Chemical Professional Committee 1983). The soil was air dried, passed through a 2-mm nylon sieve before use, and the background concentrations of $\mathrm{Cu}, \mathrm{Zn}, \mathrm{Pb}, \mathrm{Cd}$ and $\sum \mathrm{PAHs}$ were determined to be $46.0 \pm 1.5$, $148 \pm 2,48.5 \pm 4.7,2.73 \pm 0.24$ and $2.31 \pm 0.31 \mathrm{mg} \mathrm{kg}^{-1}$, respectively.

Water spinach (Ipomoea aquatica Fork.) was selected because of its tolerance and resistance to both inorganic and organic pollutants (Bhaduri and Fulekar 2012; Xin et al. 2013). The seeds were bought from Jiangsu Provincial Academy of Agricultural Sciences (JAAS). 


\section{Seed germination tests}

Batches of soil $(200 \mathrm{~g} \times 3)$ were adjusted to concentrations of OTC of $0,0.01,0.05,0.1,0.2,0.5,1,5$ and $10 \mathrm{mg} \mathrm{kg}^{-1}$ soil by spraying with $5-\mathrm{mL}$ stock solutions in acetone in $15-\mathrm{cm}-$ diameter glass Petri dishes. All the seeds were surface sterilized by immersion in $10 \%$ sodium hypochlorite solution for $10 \mathrm{~min}$ (USEPA 1996), rinsed three times with distilled water, soaked in distilled water for $2 \mathrm{~h}$ and finally, sown in the prepared Petri dishes. Three replicates of each treatment were set up, and 100 pre-treated seeds of uniform size were sown with equal spacing in each dish. The dishes were placed in the dark in a growth chamber at $25 \pm 1{ }^{\circ} \mathrm{C}$ for $48 \mathrm{~h}$ before the germination test was halted. The germination status of each treatment was checked, seedling root length was measured and the biomass in each dish was determined by fresh weight (FW). Root length was defined as the length from the root tip to root radicle. The seeds were considered to have germinated when the root length was over $5 \mathrm{~mm}$ (Wang et al. 2001). Enzyme activities and important indicators related to plant defence mechanisms comprising total protein content, and the activities of peroxidase (POD), superoxide dismutase (SOD) and catalase (CAT) were determined on fresh samples immediately after the germination test or stored at $-20^{\circ} \mathrm{C}$ for less than 3 days before use.

\section{Plant whole growth stage toxicity tests}

The sub-chronic toxicity of OTC to plant growth was assayed using the following method. Pots of soil $(1.5 \mathrm{~kg} \times 3)$ were adjusted to concentrations of OTC of $0,1,4,10$ and $25 \mathrm{mg} \mathrm{kg}^{-1}$ soil by spraying with $50-\mathrm{mL}$ stock solutions in acetone. The same volumes of pure acetone without OTC were also sprayed onto the control soil. After evaporation of the acetone, the thoroughly mixed soil was adjusted to $60 \%$ of water holding capacity before use. There were three replicates of each treatment, and three germinated seedlings of uniform height were transplanted with equal spacing in each pot and cultivated under the same chamber conditions as used for the germination tests. After 60 days, the photosynthetic rate, transpiration rate, stomatal conductance and intercellular $\mathrm{CO}_{2}$ concentration of ten randomly chosen leaves were measured and recorded. Leaf samples of both the control and the 25$\mathrm{mg} \mathrm{kg}{ }^{-1}$ OTC group were also collected for the observation of ultrastructure. The shoots and roots were harvested for the determination of the parameters biomass, total protein content and activities of SOD, POD and CAT.

\section{Determination of physiological and biochemical indices}

Analysis of all the indices was performed in triplicate by picking whole seedlings from each Petri dish from the germination tests and the shoots and roots from each pot of the plant growth tests. After cutting into pieces and mixing thoroughly in an ice-cold bath, fresh plant samples of about $1.0 \mathrm{~g}$ were homogenised by grinding in ice-cold $50 \mathrm{mmol} \mathrm{L}^{-1}$ potassium phosphate buffer (PBS with $\mathrm{pH}$ 7.8) and centrifuged at $6000 \mathrm{rev} \mathrm{min}^{-1}$ at $4{ }^{\circ} \mathrm{C}$ for $20 \mathrm{~min}$. The supernatant was used for activity analysis of antioxidant enzymes. The protocols of protein extraction were determined according to the Bradford method (1976) with bovine serum albumin using A048-3 assay kits. SOD activity was determined by measuring its capacity to inhibit the photochemical reduction of NBT (Giannopolitis and Ries 1977) with A001-1 assay kits. One unit of SOD activity is defined as the amount of enzyme inhibiting $50 \%$ of the initial reduction of NBT under light, expressed as units $\mathrm{mg}^{-1}$ protein. POD activity determination was based on the observation of absorbance changes in the reaction solution $(60 \mathrm{~s}$ after the reaction started) at $470 \mathrm{~nm}$ (Noreen and Ashraf 2009) with an A084-1 assay kit. POD can catalyse the transformation of guaiacol to tetraguaiacol in the presence of $\mathrm{H}_{2} \mathrm{O}_{2}$. One unit of POD activity, expressed as unit $\mathrm{mg}^{-1}$ protein, was defined as the amount of enzyme required for formation of $1 \mu \mathrm{moL}$ of tetraguaiacol in $60 \mathrm{~s}$ at room temperature. CAT activity was calculated by measuring the decrease due to $\mathrm{H}_{2} \mathrm{O}_{2}$ decomposition with spectrophotometric assay at $405 \mathrm{~nm}$, using the A004 assay kit. One unit of CAT activity (one unit per mg protein) was defined as the amount that decomposes $1 \mu \mathrm{moL}$ of $\mathrm{H}_{2} \mathrm{O}_{2}$ per second per milligram protein.

\section{Biolog analysis}

Biolog Eco plates were used to study the substrate utilization pattern of soil microbial communities. After the plants were harvested, fresh soil ( $5 \mathrm{~g}$ ) from each treatment was sieved and added to $100 \mathrm{~mL}$ of distilled water in a $250-\mathrm{mL}$ conical flask and shaken at $200 \mathrm{rev} \mathrm{min}^{-1}$ for $20 \mathrm{~min}$. Tenfold serial dilutions were made, and 1000-fold soil dilution solution was used for injection into the wells of the Biolog Eco plates. Plates were incubated at $25{ }^{\circ} \mathrm{C}$ for 7 days, and colour development was measured daily as difference in absorbance (A) at $590 \mathrm{~nm}$ using a $\mu$ Quant microplate spectrophotometer (BioTek, Winooski, VT) before the data were calculated using Gen5 v1.06 software. Average well colour development (AWCD) values over time for all $\mathrm{C}$ sources were calculated as a measure of total microbial activity. Mean values $(n=3)$ of AWCD for the different treatments over time were compared at the $5 \%$ level of significance to evaluate their effects (Yao et al. 2000).

The average well colour development:

$$
\mathrm{AWCD}=\sum_{i=1}^{n}\left(C_{i}-R\right) / n
$$

$C_{l}$ - the colour absorbance value of reaction well; $R$ - the colour absorbance value of control well; $n$-the carbon source number, 31 . 
The Shannon index reflects both the substrate richness and the substrate evenness of test microorganisms. Shannon measures are shown to be the only standard diversity measures that can be decomposed into meaningful independent alpha and beta components when community weights are unequal (Jost, 2007). Shannon diversity index:

$H=-\sum_{i}^{n} P_{i} \times \ln P_{i}$

$P_{i}$ - each reaction well subtracting the absorbance value of the control well and then dividing by the summed colour absorbance value of 31 wells.

Evenness index:

$E=H / \ln S$

$H$-Shannon index; $S$ - the carbon source number of Biolog Eco plate, 31 for maximum.

The Simpson index, weighted toward the abundances of the most common species, is used to emphasize the dominant population of soil microorganisms (Simpson, 1949). Simpson index:

$D=1-\sum_{i=1}^{n} p_{i}^{2}$

McIntosh index indicates the evenness or homogeneity of soil microorganisms (McIntosh, 1967) and reflects the consistency of bacteria in the multidimensional rhizosphere here. McIntosh index:

$U=\sqrt{\left(\sum_{i=1}^{n} p_{i}^{2}\right)}$

All the data were processed with Microsoft Excel 2013 and the SPSS v.18.0 software package. The data were analysed for significant differences from the control treatment or between treatments using one-way analysis of variance. To highlight the principal directions of variation of the toxicity results, principal component analysis (PCA) was conducted with the SPSS v.18.0 software package, too.

\section{Results and discussion}

\section{Acute phytotoxicity of OTC}

The results of the acute phytotoxicity tests indicate that during the seed germination stage, inhibition of water spinach germination occurred in almost all the treatments compared to that in the control (Table 1), with a significant $(p<0.01)$ increase in inhibition rate to $13 \%$ at $0.01 \mathrm{mg}$ OTC kg-1 soil and $20 \%$ at

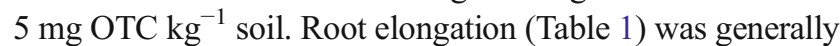
inhibited from about -23 to $-24 \%$ under the doses of 0.2 and $0.5 \mathrm{mg}$ OTC kg ${ }^{-1}$ soil but sharply inhibited to $-55 \%$ at $10 \mathrm{mg}$ OTC kg ${ }^{-1}$ soil $(p<0.01)$, which means significant promotion of root elongation appeared at most of the spiked concentrations of OTC. Biomass of water spinach did not present a clear trend at different soil concentrations of OTC (Table 1). No significant change $(p<0.05)$ of the total biomass appeared in the different treatments.

The water spinach root elongations were more susceptible to OTC at the different concentrations (Table 1). It was not linearly correlated with the increase in OTC concentration, although extremely significant difference occurred at $0.2,0.5$ and $10 \mathrm{~m} \mathrm{~kg}^{-1}(p<0.01)$; the sensitivity of results to evaluate the acute toxicity of OTC do not so agree with those for lettuce (Lactuca sativa), alfalfa (Medicago sativa) or carrot (Daucus carota) reported by Hillis et al. (2011). Desorption of heavy

Table 1 Effects of OTC on germination, root elongation, biomass and total protein content, SOD, POD and CAT activities of water spinach during germination

\begin{tabular}{|c|c|c|c|c|c|c|c|}
\hline $\begin{array}{l}\text { OTC concentration } \\
\left(\mathrm{mg} \mathrm{kg}^{-1}\right)\end{array}$ & $\begin{array}{l}\text { Germination } \\
\text { inhibition (\%) }\end{array}$ & $\begin{array}{l}\text { Root elongation } \\
\text { inhibition (\%) }\end{array}$ & $\begin{array}{l}\text { Total biomass } \\
\text { per } 100 \text { seeds }(\mathrm{g})\end{array}$ & $\begin{array}{l}\text { Total protein content } \\
\left(\mathrm{mg} \mathrm{g} \mathrm{FW}^{-1}\right)\end{array}$ & $\begin{array}{l}\text { SOD } \\
\left(\mathrm{Ug} \mathrm{FW}^{-1}\right)\end{array}$ & $\begin{array}{l}\text { POD } \\
\left(\mathrm{U} \mathrm{mg} \mathrm{pr.}^{-1}\right)\end{array}$ & $\begin{array}{l}\text { CAT } \\
\left(\mathrm{U} \mathrm{ml}^{-1}\right)\end{array}$ \\
\hline 0 & 0 & 0 & $23.31 \pm 0.25$ & $0.030 \pm 0.002$ & $113.9 \pm 18.2$ & $16.08 \pm 3.52$ & $142.6 \pm 25.6$ \\
\hline 0.01 & $13.0 \pm 1.9^{* *}$ & $-18.7 \pm 8.1^{*}$ & $24.29 \pm 0.45$ & $0.009 \pm 0.010^{* *}$ & $64.9 \pm 15.1^{*}$ & $40.23 \pm 4.66^{* *}$ & $145.6 \pm 33.9$ \\
\hline 0.05 & $0 \pm 1.3$ & $-16.4 \pm 11.2^{*}$ & $23.20 \pm 0.23$ & $0.021 \pm 0.009$ & $130.5 \pm 19.8$ & $32.95 \pm 4.92 * *$ & $134.7 \pm 28.4$ \\
\hline 0.1 & $7.0 \pm 1.2^{*}$ & $6.5 \pm 6.2$ & $23.20 \pm 0.32$ & $0.025 \pm 0.007$ & $80.1 \pm 18.6$ & $21.58 \pm 6.02$ & $182.9 \pm 32.2$ \\
\hline 0.2 & $3.0 \pm 0.2$ & $-24.3 \pm 7.7 * *$ & $23.13 \pm 0.35$ & $0.008 \pm 0.009 * *$ & $177.0 \pm 17.3^{*}$ & $16.85 \pm 6.34$ & $300.8 \pm 31.5^{* *}$ \\
\hline 0.5 & $3.0 \pm 0.9$ & $-23.1 \pm 7.5^{* *}$ & $23.15 \pm 0.19$ & $0.016 \pm 0.006^{* *}$ & $276.5 \pm 19.2^{* *}$ & $18.57 \pm 4.97$ & $137.0 \pm 25.6$ \\
\hline 1 & $1.0 \pm 1.1$ & $5.3 \pm 5.8$ & $23.38 \pm 0.24$ & $0.019 \pm 0.003 * *$ & $95.6 \pm 14.9$ & $41.56 \pm 5.28 * *$ & $315.9 \pm 22.2 * *$ \\
\hline 5 & $20.0 \pm 1.2 * *$ & $1.3 \pm 6.1$ & $22.84 \pm 0.43$ & $0.015 \pm 0.005 * *$ & $129.3 \pm 21.3$ & $29.35 \pm 1.87 * *$ & $257.1 \pm 30.8^{* *}$ \\
\hline 10 & $9.0 \pm 1.3^{*}$ & $-55.1 \pm 9.8^{* *}$ & $22.81 \pm 0.44$ & $0.053 \pm 0.007 * *$ & $238.4 \pm 19.7 * *$ & $42.12 \pm 3.79 * *$ & $404.4 \pm 29.8^{* *}$ \\
\hline
\end{tabular}

Values are the average of three replicates \pm standard deviation (SD)

*It means significantly different from treatment without OTC addition $(p<0.05)$

$* *$ It means highly significant different from treatment without OTC addition $(p<0.01)$ 
metal ions (including cadmium) occurs under the competitive adsorption effect of OTC in soils, and this may explain the inhibition of germination observed (Sawidis 2008; Wan et al. 2010). Metal-centric toxicity at low addition rates of OTC occurred, particularly in heavy metal-contaminated soil, so that the existence of $\mathrm{Cd}$ in soil might affect the germination rates significantly. The sudden increase in toxicity at high rates OTC might represent a combined effect of the high dose of OTC and the influence of desorbed pollutants.

In other researches, antibiotics, chloramphenicol (CHL), florphenicol (FLO) and OTC inhibited growth of Tetraselmis suecica with 96-h IC50 values in the order of OTC > CHL > FLO (Seoane et al., 2014). In accordance to the standard procedures, the acute toxicities (48-h EC50 value, mg/L) in decreasing order were oxolinic acid (OA) (4.6), tiamulin (TI) (40), sulfadiazine (SU) (221), streptomycin (ST) (487), tylosin (TY) (680) and OTC ( 1000) to the freshwater crustacean Daphnia magna (Wollenberger et al., 2000).

The biochemical index total protein content (Table 1) was inhibited at OTC exposure below $5 \mathrm{mg} \mathrm{kg}^{-1}$ soil but was significantly promoted when the OTC concentration increased to $10 \mathrm{mg} \mathrm{kg}^{-1}$. SOD activity (Table 1) decreased slightly at OTC stress below $0.01 \mathrm{mg} \mathrm{kg}^{-1}$ and then showed a stimulated trend when the OTC stress exceeded $0.2,0.5$ and $10 \mathrm{mg} \mathrm{kg}^{-1}$. A similar trend in POD activity was observed (Table 1). After elevation at $0.01 \mathrm{mg} \mathrm{OTC} \mathrm{kg}^{-1}$ soil, POD activity declined with further increase in exposure concentration $(0.01$ to $0.5 \mathrm{mg}$ OTC kg-1 soil) and then a second peak appeared at $1 \mathrm{mg}$ OTC $\mathrm{kg}^{-1}$ soil. CAT activity also showed an upward trend except for a low point at $0.5 \mathrm{mg} \mathrm{OTC} \mathrm{kg}^{-1}$ soil stress (Table 1).

The antioxidant status was of great importance as an indicator of physiological functions against the stress from environmental pollutants. Environmental stress leads to increasing oxygen free radical levels and disturbs the anti-oxidative balance in plants, animals and microorganisms (Bernanke and Köhler 2009). Generally, total protein content has been shown to decrease when expressed in a toxic environment (Santos et al. 1993), perhaps mainly due to the consumption of enzymes as a defence mechanism for plants in the short term or because of the inhibition or blocking of protein synthesis by OTC. However, the clear increase at $10 \mathrm{mg} \mathrm{OTC} \mathrm{kg}^{-1}$ soil may be related to the accelerated synthesis of antioxidant enzymes under the stimulation of OTC, which might provide enough enzymes in the defence against pollutants in water spinach.

When OTC induced oxidative stress and disturbed the antioxidant balance, the water spinach initiated anti-oxidation and detoxification responses against OTC exposure by strengthening anti-oxidative enzyme synthesis. As previous assays have shown, SOD performed the function of transforming reactive $\mathrm{O}_{2}$ species (ROS) into hydrogen peroxide, constituting the first line of defence against excess ROS under stress conditions (Fridovich 1995). Thus, the increase in SOD activity indicates the presence of toxicity. In the tests, the initial decrease in SOD activity was supposed to be the consumption against the rising ROS with the trend in promotion of enzyme activity occurring at OTC addition rates from 0.1 to $0.5 \mathrm{mg} \mathrm{kg}^{-1}$ soil, suggesting the response of water spinach to adverse conditions. The minimum dose of OTC to activate SOD defence mechanism was observed, as in previous assays, which showed that the detoxification system was stimulated at a certain exposure concentration (Bigorgne et al. 2011). POD and CAT perform the role of splitting hydrogen peroxide into water and oxygen as found frequently in fishes and plants in some studies (Verma and Dubey 2003; Woo et al. 2009; Wang et al. 2012). Since SOD increased at $0.1-0.5 \mathrm{mg}$ OTC $\mathrm{kg}^{-1}$ soil, more hydrogen peroxide was produced from ROS, resulting in high consumption of POD and CAT within any specified OTC dose. There is also a synergism between SOD and CAT in defence mechanisms. The depleting of SOD and CAT will definitely reduce the overall activity of CAT in some way. The SOD results showing specific inhibition at $1 \mathrm{mg}$ OTC $\mathrm{kg}^{-1}$ soil indicate that the
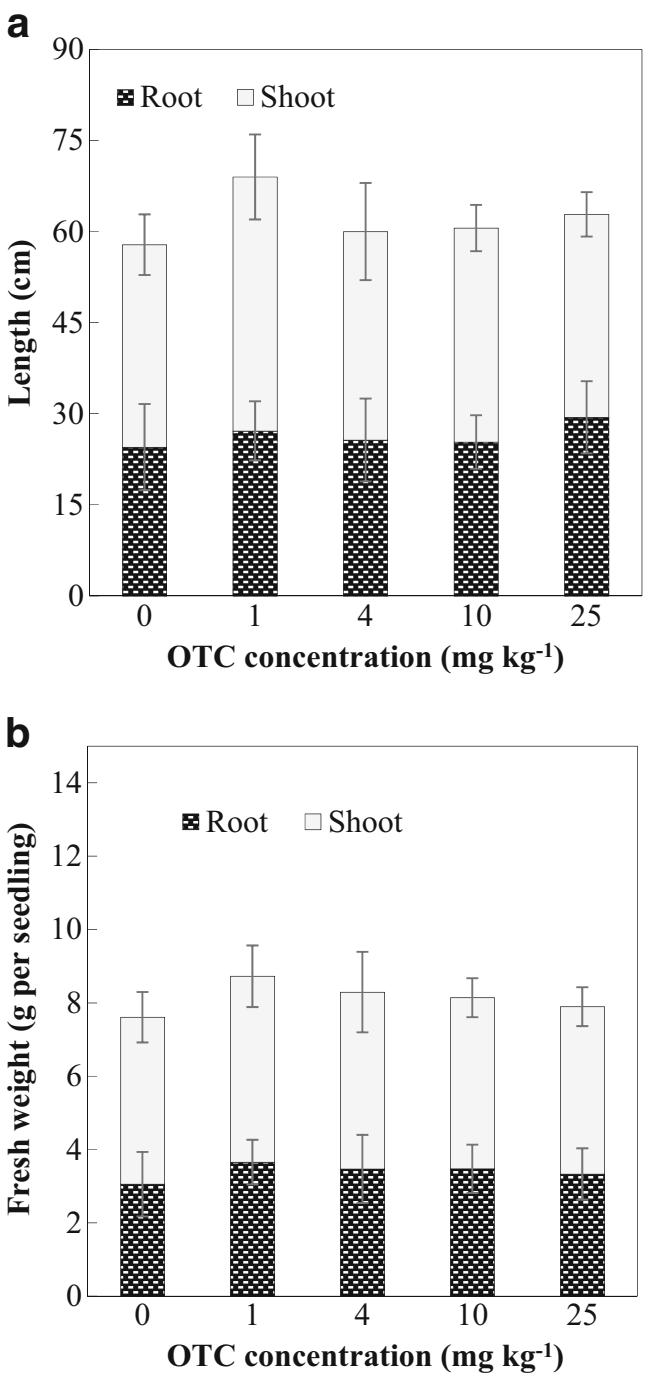

Fig. 1 Effects of OTC on the length and fresh weight of the shoots and roots 
Table 2 Effects of OTC on total protein content, SOD, POD and CAT activities of water spinach during the seedling stage

\begin{tabular}{llllll}
\hline Sample & $\begin{array}{l}\text { OTC concentration } \\
\left(\mathrm{mg} \mathrm{kg}^{-1}\right)\end{array}$ & $\begin{array}{l}\text { Total protein content } \\
\left(\mathrm{mg} \mathrm{g} \mathrm{FW}^{-1}\right)\end{array}$ & $\begin{array}{l}\mathrm{SOD} \\
\left(\mathrm{U} \mathrm{g} \mathrm{FW}^{-1}\right)\end{array}$ & $\begin{array}{l}\text { POD } \\
\left(\mathrm{U} \mathrm{mg} \mathrm{pr.}^{-1}\right)\end{array}$ & $\begin{array}{l}\text { CAT } \\
\left(\mathrm{U} \mathrm{ml}^{-1}\right)\end{array}$ \\
\hline Leaf & 0 & $41.75 \pm 1.09$ & $4.79 \pm 0.52$ & $28.74 \pm 0.35$ & $0.59 \pm 0.03$ \\
& 1 & $35.18 \pm 1.84^{* *}$ & $7.10 \pm 0.99^{* *}$ & $34.61 \pm 1.66^{*}$ & $0.60 \pm 0.02$ \\
& 4 & $26.61 \pm 3.56^{* *}$ & $11.05 \pm 1.33^{* *}$ & $44.66 \pm 4.95^{* *}$ & $1.05 \pm 0.22$ \\
& 10 & $23.92 \pm 1.92^{* *}$ & $11.35 \pm 2.02^{* *}$ & $49.63 \pm 3.62^{* *}$ & $1.15 \pm 0.34$ \\
& 25 & $33.51 \pm 5.18^{*}$ & $5.74 \pm 0.81^{*}$ & $27.81 \pm 0.38^{*}$ & $0.24 \pm 0.13^{*}$ \\
Root & 0 & $25.84 \pm 2.07$ & $9.25 \pm 1.41$ & $42.29 \pm 3.95$ & $0.20 \pm 0.10$ \\
& 1 & $17.44 \pm 1.15^{* *}$ & $14.68 \pm 1.04^{* *}$ & $63.05 \pm 5.57^{* *}$ & $0.53 \pm 0.08^{*}$ \\
& 4 & $17.60 \pm 0.50^{* *}$ & $13.54 \pm 0.74^{* *}$ & $63.47 \pm 2.67^{* *}$ & $0.45 \pm 0.23$ \\
& 10 & $19.56 \pm 2.99$ & $12.79 \pm 2.67$ & $54.20 \pm 10.45$ & $0.77 \pm 0.31^{*}$ \\
& 25 & $18.30 \pm 0.76^{* *}$ & $13.89 \pm 0.95^{*}$ & $59.63 \pm 2.48^{* *}$ & $1.17 \pm 0.11^{* *}$ \\
\hline
\end{tabular}

Values are the average of three replicates \pm SD

$*$ It means significantly different from treatment without OTC addition $(p<0.05)$

**It means highly significantly different from treatment without OTC addition $(p<0.01)$ threshold of the defence system was exceeded (Kono and Fridovich 1982). Anti-oxidation and detoxification systems were disturbed and might result in an inhibition of enzymes directly or indirectly because metabolic disorder, tissue damage or other toxicologically relevant responses might be induced by ROS (Zhou et al. 2010). To resist even higher doses of OTC, stronger defence mechanisms might be applied as test results showed that a larger amount of SOD, POD and CAT were synthesized under stimulation of even higher OTC addition rates (1 to $10 \mathrm{mg} \mathrm{kg}^{-1}$ soil).

\section{Sub-chronic phytotoxicity of OTC}

Plant growth tests were conducted for 60 days to investigate the effects in whole growth stage of water spinach seedlings under different rates of OTC. At the end of the plant growth test, the residual OTC concentrations were $0.22 \pm 0.03,0.50 \pm$ $0.04,2.16 \pm 0.20$ and $5.19 \pm 0.32 \mathrm{mg} \mathrm{kg}^{-1}$ in soil, decreasing by $78.0,87.5,78.4$ and $79.2 \%$, respectively, compared to the initial OTC concentrations of 1, 4, 10 and $25 \mathrm{mg} \mathrm{kg}^{-1}$. Among all the indices determined, the length and biomass (FW) of the shoots and roots of seedlings showed no significant change compared to that in the control (Fig. 1) in general.

The biochemical indices of total protein content, SOD, POD and CAT were measured in the leaves and roots after harvest. As shown in Table 2, total protein content was inhibited without obvious differences among the treatments in the roots and with a gradual decrease in the leaves. The leaves had higher total protein contents, which increased at an OTC rate of $25 \mathrm{mg} \mathrm{kg}^{-1}$ soil compared with the roots. The changes in both SOD and POD activities in the leaves were similar to those of the roots (Table 2). Activities of SOD and POD were promoted by OTC, exhibiting a decrease in the leaves and remaining stable in the roots at OTC rates less than $10 \mathrm{mg} \mathrm{kg}^{-1}$ soil. However, at an OTC level of $25 \mathrm{mg} \mathrm{kg}^{-1}$, the activities of both SOD and POD in the leaves were inhibited and similar to those in the controls. Unlike SOD and POD, CAT activity was higher in the leaves in all the treatment except $25 \mathrm{mg}$ OTC kg${ }^{-1}$ soil. CAT activity increased continuously in both the leaves and roots with increasing OTC level but at $25 \mathrm{mg}$ OTC kg${ }^{-1}$ soil, the foliar CAT activity declined markedly to levels even lower than that in the controls.

Table 3 Effects of OTC on photosynthetic rate, transpiration rate, stomatal conductance and water use efficiency of water spinach

\begin{tabular}{|c|c|c|c|c|c|}
\hline \multirow[t]{2}{*}{ Parameter } & \multicolumn{5}{|c|}{ Initial OTC concentration $\left(\mathrm{mg} \mathrm{kg}^{-1}\right)$} \\
\hline & 0 & 1 & 4 & 10 & 25 \\
\hline Photosynthetic rate/ $\mu \mathrm{moL} \mathrm{CO} 2\left(\mathrm{~m}^{2} \cdot \mathrm{s}\right)$ & $14.159 \pm 1.054$ & $11.814 \pm 2.713$ & $11.139 \pm 1.974$ & $6.900 \pm 1.904^{* *}$ & $6.409 \pm 0.244^{* *}$ \\
\hline Transpiration rate $/ \mathrm{mmoL}_{2} \mathrm{O}\left(\mathrm{m}^{2} \cdot \mathrm{s}\right)$ & $3.035 \pm 0.637$ & $2.292 \pm 0.732$ & $2.017 \pm 0.230^{*}$ & $1.192 \pm 0.286^{* *}$ & $1.175 \pm 0.088^{* *}$ \\
\hline Stomatal conductance $/ \mathrm{mmoL}\left(\mathrm{m}^{2} \cdot \mathrm{s}\right)$ & $0.133 \pm 0.038$ & $0.112 \pm 0.034$ & $0.101 \pm 0.006$ & $0.057 \pm 0.0115^{* *}$ & $0.059 \pm 0.007 * *$ \\
\hline Water use efficiency/mmoL $\mathrm{CO}_{2} \mathrm{moL} \mathrm{H}_{2} \mathrm{O}$ & $4.733 \pm 0.647$ & $5.125 \pm 0.472$ & $5.494 \pm 0.401$ & $5.783 \pm 0.213 * *$ & $5.339 \pm 0.137$ \\
\hline
\end{tabular}

Values are the average of three replicates \pm SD

*It means significantly different from treatment without OTC addition $(p<0.05)$

**It means highly significantly different from treatment without OTC addition $(p<0.01)$ 
Fig. 2 TEM images of water spinach leaves with and without OTC treatment (a and c, control; b and d, $25 \mathrm{mg} \mathrm{OTC} \mathrm{kg}^{-1}$ soil; a and $\mathbf{b}$ at $2000 \times$; $\mathbf{c}$ and $\mathbf{d}$ at $5000 \times$ )
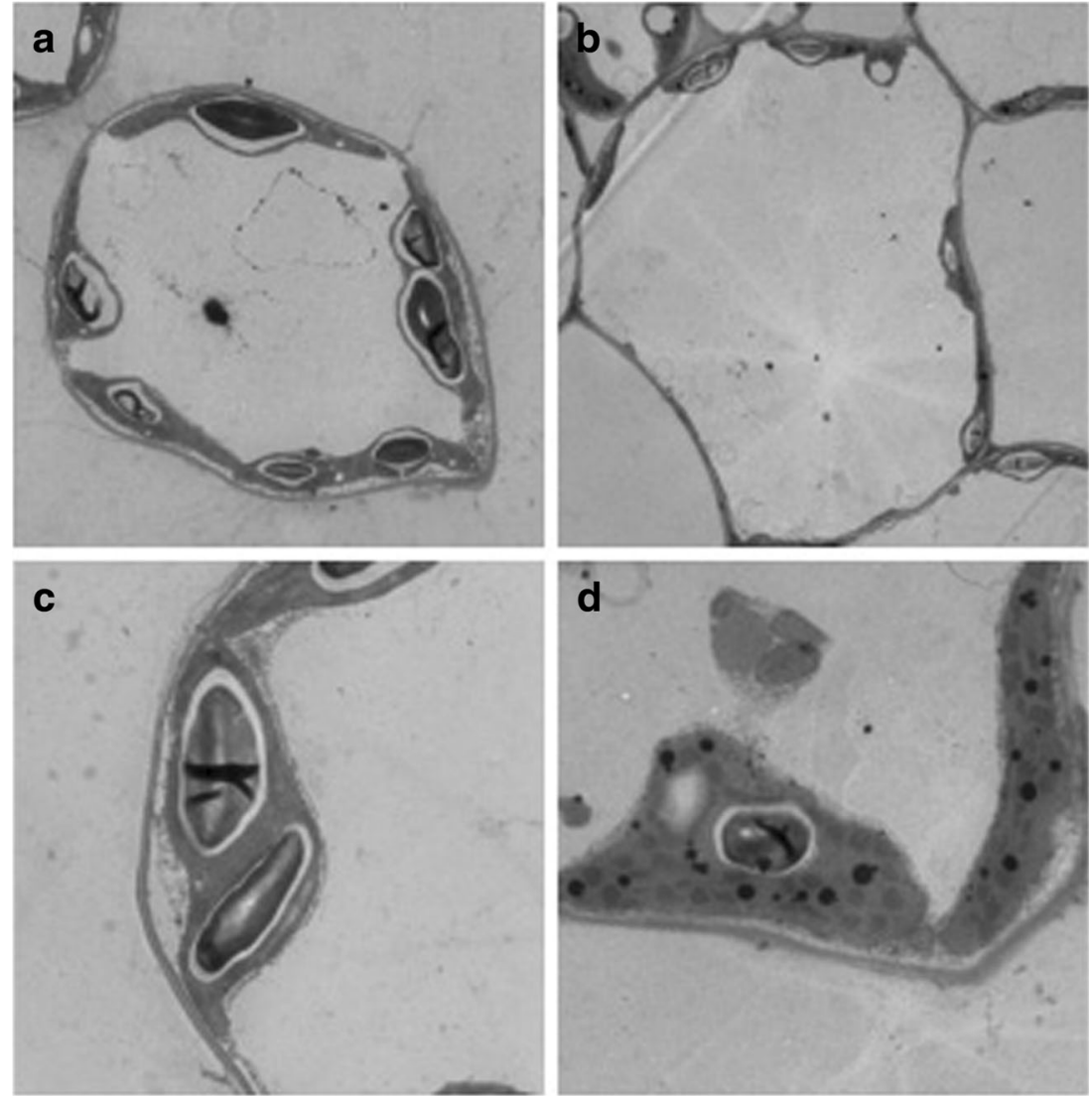

Spinach has been reported to be highly tolerant to many abiotic stresses (Shimazaki et al. 1992; Fan et al. 2012). Tolerant plant species protect themselves by using strong defence mechanisms, mostly as intensified antioxidant enzyme activity, and specialization of plant tolerance may be related to the influence of tissue and subcellular localization of enzymes and upstream sequences in the genomic sequence (Wilhelm 2006; Sánchez-Rodríguez et al. 2011; Mittal et al. 2012). In the plant growth tests, the leaves contained more total protein for their enhanced metabolic activities. Higher levels of SOD and POD activities in the roots resulted from the direct stimulation of toxic compounds in the rhizosphere, which in turn contributed to the tolerance of the roots against the toxic environment. At an OTC level of $25 \mathrm{mg} \mathrm{kg}^{-1}$ soil, CAT activity in the roots also exceeded that in the leaves. Compared to the leaves, the roots showed higher tolerance to OTC stress as shown by increasing the amount of synthetic anti-oxidative enzymes as the increasing OTC level. Anti-oxidative enzymes in the leaves decreased sharply at $25 \mathrm{mg} \mathrm{OTC} \mathrm{kg}^{-1}$, indicating a collapse of defence systems and interference with plant
Fig. 3 Changes in AWCD values under the different treatments

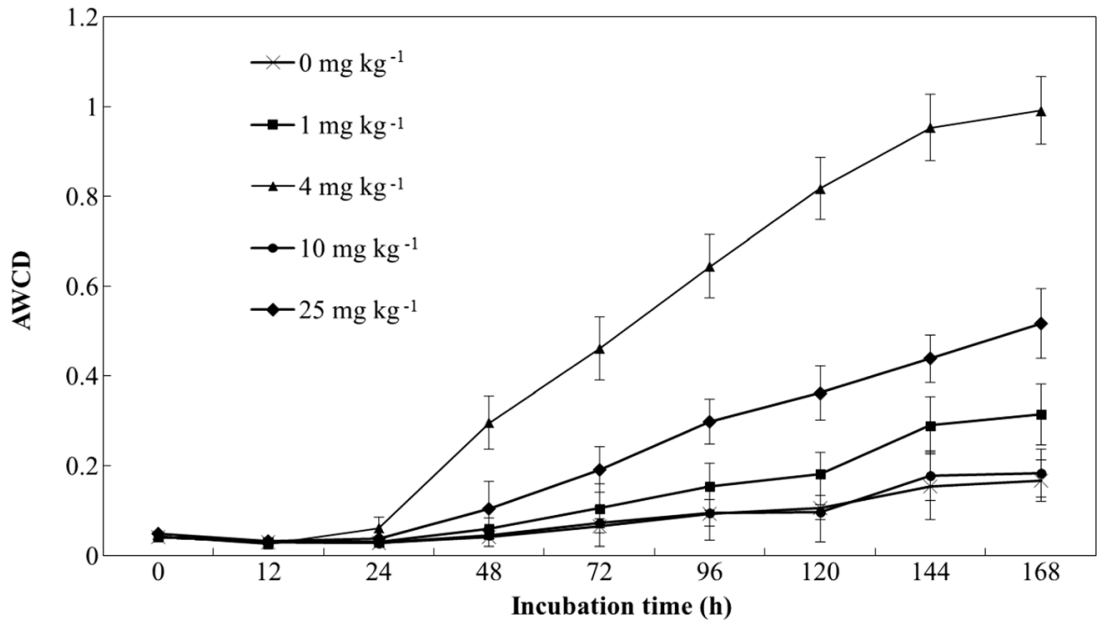




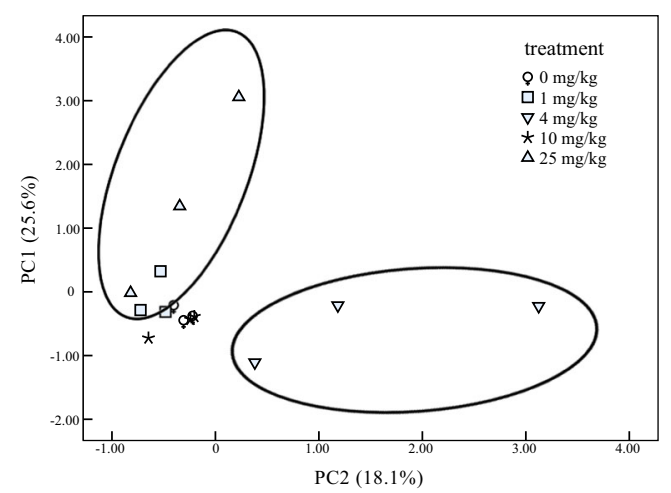

Fig. 4 Principal component analysis (PCA) results of substrate utilization potential of the soil microbial community

physiological activities. Total protein content in the leaves was also seriously shut down at the highest OTC level, demonstrating possible damage to functional tissues related to metabolism.

Physiological indices related to metabolism were determined before the plants were harvested (Table 3). Results show that photosynthetic rates, transpiration rates and stomatal conductance exhibited a downward trend as the OTC level increased and were significantly reduced at $10 \mathrm{mg}$ OTC kg-1, illustrating the sub-chronic negative effect of OTC on water spinach. Water use efficiency (WUE) is an important agronomic character that also decreased slightly at the highest OTC stress (Table 3). Combined with related assays showing that damage to plant tissues may reduce WUE (Shan et al. 1996; Reich et al. 1985) and the marked reduction in enzyme activities in the leaves (Table 2), it can be inferred that OTC might injure the functional tissues in the leaves. Leaf ultrastructure was observed using transmission electron microscopy (TEM) to demonstrate this assumption. Comparing Fig. 2a and $b$, starch grains decreased sharply in number and in size. Starch grains play an important role in the deposition of photosynthetic products. When the photosynthetic process was inhibited or slowed down, the accumulation rate of the plants could not match the hydrolysis rate. Comparing Fig. $2 \mathrm{c}$ and d, a large number of osmiophilic bodies were found in the tissues of the OTC-treated plants. Osmiophilic bodies are often observed in damaged tissues within multiple assays and are considered necessary in the rebuilding of the integrity of the plasma membrane (Pareek et al. 1997), and this confirms that the foliar tissues were damaged by high rates of OTC in sub-chronic toxicity experiments.

In former investigations, it has been found that OTC concentrations range from 0 to $25 \mathrm{mg} \mathrm{L}^{-1}$ in concentration compete for adsorption sites on the surface of soils with heavy metal contamination, and as a result, the HM desorption rate increases with increasing OTC concentration (Chen et al. 2014). However, when the OTC concentration ranges from 25 to $100 \mathrm{mg} \mathrm{L}^{-1}$, some free $\mathrm{HM}$ ions form complexes with OTC and become fixed again on the surfaces of the soil matrix (Chen et al. 2014). The changes in HM availability in contaminated soils are mostly attributed to competition for adsorption sites, and complexation reactions between OTC and HMs, together with changes in $\mathrm{pH}$, upset the dynamic equilibrium (adsorption and desorption) of the soil pollutants.

\section{Biolog Eco tests}

In these tests, soil microbial diversity in soil samples from the plant growth tests was evaluated using Biolog Eco tests. According to Fig. 3, average well colour development (AWCD) values at treatment with $4 \mathrm{mg}$ OTC kg-1 were extremely high, followed by 25 and $1 \mathrm{mg}$ OTC kg${ }^{-1}$, and $10 \mathrm{mg}$ OTC $\mathrm{kg}^{-1}$, and the controls showed the lowest values. AWCD values did not change initially but then increased rapidly after $48 \mathrm{~h}$. The AWCD values at 1, 4, 10 and $25 \mathrm{mg} \mathrm{OTC} \mathrm{kg}^{-1}$ were $88.9,495,10.5$ and $211 \%$ higher than those at the controls after incubation for $168 \mathrm{~h}$.

The Shannon index showed a visible decline at $4 \mathrm{mg}$ OTC $\mathrm{kg}^{-1}(p<0.05)$ but no significant differences among the treatments in line with the conclusion of Zielezny et al. (2006) were shown, except that the values of the OTC-treated soils were all lower than those of the control. Evenness showed a similar trend with the values of each treatment following the order: $0>10>1,4$ and $25 \mathrm{mg} \mathrm{kg}^{-1}$ and no significant differences
Table 4 Indices of microbial diversity

\begin{tabular}{|c|c|c|c|c|c|}
\hline \multirow[t]{2}{*}{ Index } & \multicolumn{5}{|c|}{ Initial OTC concentration $\left(\mathrm{mg} \mathrm{kg}^{-1}\right)$} \\
\hline & 0 & 1 & 4 & 10 & 25 \\
\hline Shannon & $1.487 \pm 0.258$ & $0.889 \pm 0.385^{*}$ & $0.832 \pm 0.088^{* *}$ & $1.112 \pm 0.236$ & $1.026 \pm 0.226$ \\
\hline Simpson & $0.575 \pm 0.043$ & $0.718 \pm 0.126$ & $0.726 \pm 0.029 * *$ & $0.646 \pm 0.046$ & $0.555 \pm 0.229$ \\
\hline McIntosh & $1.336 \pm 0.551$ & $1.709 \pm 0.633$ & $3.998 \pm 1.368^{* *}$ & $1.334 \pm 0.171$ & $3.904 \pm 0.647 * *$ \\
\hline Evenness & $0.608 \pm 0.022$ & $0.339 \pm 0.191 *$ & $0.313 \pm 0.05^{* *}$ & $0.448 \pm 0.064^{* *}$ & $0.327 \pm 0.072 * *$ \\
\hline
\end{tabular}

Values are the average of three replicates \pm SD

*It means significantly different from treatment without OTC addition $(p<0.05)$

**It means highly significantly different from treatment without OTC addition $(p<0.01)$ 
among the OTC concentrations. The Simpson index at $4 \mathrm{mg}$ OTC $\mathrm{kg}^{-1}$ and the McIntosh index at 4 and $25 \mathrm{mg} \mathrm{kg}^{-1}$ were markedly higher than those at the control, in accordance with the AWCD results.

Principal component analysis of the Eco plate data shows the effects of OTC on substrate utilization in rhizosphere soil (Fig. 4). Statistical analysis was conducted using the SPSS software package with two principal components (25.6 and $18.1 \%$ of the total variance). Treatments with 4 and $25 \mathrm{mg}$ OTC $\mathrm{kg}^{-1}$ were divided from the other treatments and the control.

In Biolog Eco plate analysis, the microbial activities were generally promoted by addition of OTC, and the degree of promotion was not linearly correlated with the addition rate of OTC (Fig. 3 and Table 4). Microbial diversity and evenness were also influenced by OTC according to changes in the indices. Principal component analysis (PCA) indicates that the contributions of rhizosphere microorganisms in the utilization of substrate were greatly influenced by the addition of OTC at particular levels. At $4 \mathrm{mg}$ OTC kg${ }^{-1}$ soil, L-arginine, B-methyl-D-glucoside, N-acetyl-D-glucosamine, L-asparagine and glycyl-L-glutamic acid were utilized more efficiently and

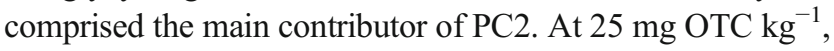
utilization of Tween 80, glycogen, D-cellobiose, a-D-lactose, $\mathrm{D}, \mathrm{L}-\mathrm{a}-$-glycerol and L-arginine was promoted, and these were the main components of $\mathrm{PC} 1$.

\section{Conclusions}

In the experimental soil, OTC inhibited the seed germination, disturbed the anti-oxidative system and damaged the functional tissues of water spinach. Microbial activity and diversity in rhizosphere soil were simultaneously affected in the variety of carbon sources utilized at different rates of addition of OTC. Considering the risk of soil OTC introduction to agricultural plants, food safety and human health, antibiotics themselves and stuff, like water and fertilizer, containing them should be strictly considered before application in the future.

Acknowledgments This research was supported jointly by the National Natural Science Foundation of China (41401581 and 41271326) and the China National High-Technology Research and Development Program (2012AA06A204)

\section{References}

Aga DS, O'Connor S, Ensley S, Payero JO, Snow D, Tarkalson D (2005) Determination of the persistence of tetracycline antibiotics and their degradates in manure-amended soil using enzyme-linked immunosorbent assay and liquid chromatography-mass spectrometry. J Agri Food Chem 53:7165-7171
Bernanke J, Köhler HR (2009) The impact of environmental chemicals on wildlife vertebrates. Rev Environ Contam Toxicol 198:1-47

Bhaduri AM, Fulekar M (2012) Assessment of arbuscular mycorrhizal fungi on the phytoremediation potential of Ipomoea aquatica on cadmium uptake. 3 Biotech 2:193-198

Bigorgne E, Foucaud L, Lapied E, Labille J, Botta C, Sirguey C, Falla J, Rose J, Joner EJ, Rodius F (2011) Ecotoxicological assessment of $\mathrm{TiO}_{2}$ byproducts on the earthworm Eisenia fetida. Environ Pollut 159:2698-2705

Boleas S, Alonso C, Pro J, Fernández C, Carbonell G, Tarazona JV (2005) Toxicity of the antimicrobial oxytetracycline to soil organisms in a multi-species-soil system (MS · 3 ) and influence of manure co-addition. J Hazard Mater 122:233-241

Boxall A, Fogg L, Blackwell P, Blackwell P, Kay P, Pemberton E, Croxford A (2004) Veterinary medicines in the environment. Rev Environ Contam Toxicol 180:1-91

Bradford MM (1976) A rapid and sensitive method for the quantitation of microgram quantities of protein utilizing the principle of protein-dye binding. Anal Biochem 72:248-254

Chen LK, Ma TT, Pan X, Luo K, Wu LH, Luo YM (2014) Sorption behaviour of oxytetracycline in complex contaminated soil and its effects on desorption of heavy metals in the soil. Acta Pedologica Sinica 52:97-104

Fan W, Zhang M, Zhang H, Zhang P (2012) Improved tolerance to various abiotic stresses in transgenic sweet potato (Ipomoea batatas) expressing spinach betaine aldehyde dehydrogenase. PLoS One 7:e37344

Farzaneh A, Adel Y, Ali N, Younes G (2013) Determine effective concentrations of $\beta$-lactam antibiotics against three strains of Agrobacterium tumefaciens and phytotoxicity on tomato and tobacco. Int J Agron Plant Prod 4:2919-2925

Fridovich I (1995) Superoxide radical and superoxide dismutases. Annu Rev Biochem 64:97-112

Gothwal R, Shashidhar T (2015) Antibiotic pollution in the environment: a review. Clean - Soil Air Water. doi: 10.1002/clen.201300989.

Gao M, Song W, Zhou Q, Ma X, Chen X (2013) Interactive effect of oxytetracycline and lead on soil enzymatic activity and microbial biomass. Environ Toxicol Pharmacol 36:667-674

Giannopolitis CN, Ries SK (1977) Superoxide dismutases II. Purification and quantitative relationship with water-soluble protein in seedlings. Plant Physiol 59:315-318

Goetsch HE, Mylon SE, Butler S, Zilles JL, Nguyen TH (2012) Oxytetracycline interactions at the soil-water interface: effects of environmental surfaces on natural transformation and growth inhibition of Azotobacter vinelandii. Environ Toxicol Chem 31:2217-2224

Hillis DG, Fletcher J, Solomon KR, Sibley PK (2011) Effects of ten antibiotics on seed germination and root elongation in three plant species. Arch Environ Contam Toxicol 60:220-232

$\mathrm{Hu}$ XG, Zhou QX, Luo Y (2010) Occurrence and source analysis of typical veterinary antibiotics in manure, soil, vegetables and groundwater from organic vegetable bases, northern China. Environ Pollut 158:2992-2998

Jost L (2007) Partitioning diversity into independent alpha and beta components. Ecol 88:2427-2439

Karc1 A, Balcığlu IA (2009) Investigation of the tetracycline, sulfonamide, and fluoroquinolone antimicrobial compounds in animal manure and agricultural soils in Turkey. Sci Total Environ 407:4652-4664

Kay P, Blackwell PA, Boxall A (2004) Fate of veterinary antibiotics in a macroporous tile drained clay soil. Environ Toxicol Chem 23:1136-1144

Kong WD, Zhu YG, Liang Y, Zhang J, Smith FA, Yang M (2007) Uptake of oxytetracycline and its phytotoxicity to alfalfa (Medicago sativa L.). Environ Pollut 147:187-193

Kono Y, Fridovich I (1982) Superoxide radical inhibits catalase. J Biol Chem 257:5751-5754

Leung AO, Cheung KC, Wong MH (2015) Spatial distribution of polycyclic aromatic hydrocarbons in soil, sediment, and combusted 
residue at an e-waste processing site in southeast China. Environ Sci Pollut Res 20:8786-8801

Li C, Chen JY, Wang JH, Ma ZH, Han P, Luan YX, Lu AX (2015) Occurrence of antibiotics in soils and manures from greenhouse vegetable production bases of Beijing, China and an associated risk assessment. Sci Total Environ 521-522:101-107

Li YW, Wu XL, Mo CH, Tai YP, Huang XP, Xiang L (2011) Investigation of sulfonamide, tetracycline, and quinolone antibiotics in vegetable farmland soil in the Pearl River Delta area, Southern China. J Agri Food Chem 59:7268-7276

Liu F, Ying GG, Tao R, Zhao JL, Yang JF, Zhao LF (2009) Effects of six selected antibiotics on plant growth and soil microbial and enzymatic activities. Environ Pollut 157:1636-1642

Martínez-Carballo E, González-Barreiro C, Scharf S, Gans O (2007) Environmental monitoring study of selected veterinary antibiotics in animal manure and soils in Austria. Environ Pollut 148:570-579

McIntosh RP (1967) An index of diversity and the relation of certain concepts to diversity. Ecol 48:392-404

Migliore L, Rotini A, Cerioli NL, Cozzolino S, Fiori M (2010) Phytotoxic antibiotic sulfadimethoxine elicits a complex hormetic response in the weed Lythrum salicaria L. Dose-Response 8:414-427

Mittal S, Kumari N, Sharma V (2012) Differential response of salt stress on Brassica juncea: photosynthetic performance, pigment, proline, D1 and antioxidant enzymes. Plant Physiol Biochem 54:17-26

Noreen Z, Ashraf M (2009) Changes in antioxidant enzymes and some key metabolites in some genetically diverse cultivars of radish (Raphanus sativus L.). Environ Exp Bot 67:395-402

Pareek A, Singla SL, Grover A (1997) Short-term salinity and high temperature stress-associated ultrastructural alterations in young leaf cells of Oryza sativa L. Anna Bot 80:629-639

Radjenović J, Petrović M, Barceló D (2009) Fate and distribution of pharmaceuticals in wastewater and sewage sludge of the conventional activated sludge (CAS) and advanced membrane bioreactor (MBR) treatment. Water Res 43:831-841

Reich PB, Schoettle AW, Amundson RG (1985) Effects of low concentrations of $\mathrm{O}_{3}$, leaf age and water stress on leaf diffusive conductance and water use efficiency in soybean. Physiologia Plantarum 63:58-64

Sánchez-Rodríguez E, Moreno DA, Ferreres F, Rubio-Wilhelmi MM, Ruiz JM (2011) Differential responses of five cherry tomato varieties to water stress: changes on phenolic metabolites and related enzymes. Phytochem 72:723-729

Santos I, Almeida J, Salema R (1993) Plants of Zea mays L. developed under enhanced UV-B radiation. I. Some ultrastructural and biochemical aspects. J Plant Physiol 141:450-456

Sarmah AK, Meyer MT, Boxall A (2006) A global perspective on the use, sales, exposure pathways, occurrence, fate and effects of veterinary antibiotics (VAs) in the environment. Chemosphere 65:725-759

Sawidis T (2008) Effect of cadmium on pollen germination and tube growth in Lilium longiflorum and Nicotiana tabacum. Protoplasma 233:95-106

Seoane M, Rioboo C, Herrero C, Cid Á (2014) Toxicity induced by three antibiotics commonly used in aquaculture on the marine microalga Tetraselmis suecica (Kylin) Butch. Mar Environ Res 101:1-7

Shan Y, Feng Z, Izuta T, Aoki M, Totsuka T (1996) The individual and combined effects of ozone and simulated acid rain on growth, gas exchange rate and water-use efficiency of Pinus armandi Franch. Environ Pollut 91:355-361

Shimazaki KI, Yu SW, Sakaki T, Tanaka K (1992) Differences between spinach and kidney bean plants in terms of sensitivity to fumigation with $\mathrm{NO}_{2}$. Plant Cell Physiol 33:267-252

Simpson EH (1949) Measurement of diversity. Nature 163:688
Subramanian A, Kunisue T, Tanabe S (2015) Recent status of organohalogens, heavy metals and PAHs pollution in specific locations in India. Chemosphere 137:122-134

The Chinese Society of Soil Agricultural Chemical Professional Committee (1983) Soil agricultural chemical routine analysis method. Science Press, Marickville

Thiele-Bruhn S, Beck IC (2005) Effects of sulfonamide and tetracycline antibiotics on soil microbial activity and microbial biomass. Chemosphere 59:457-465

Thuy HTT, Nguyen TD (2013) The potential environmental risks of pharmaceuticals in Vietnamese aquatic systems: case study of antibiotics and synthetic hormones. Environ Sci Pollut Res 20:8132-8140

USDA (2011) http://soils.usda.gov/technical/aids/investigations/texture/

USEPA (1996) Ecological effects test guidelines (OPPTS 850.4200): seed germination/root elongation toxicity test

Verma S, Dubey R (2003) Lead toxicity induces lipid peroxidation and alters the activities of antioxidant enzymes in growing rice plants. Plant Sci 164:645-655

Wan Y, Bao YY, Zhou QX (2010) Simultaneous adsorption and desorption of cadmium and tetracycline on cinnamon soil. Chemosphere 80:807-812

Wang FH, Qiao M, Lv ZE, Guo GX, Jia Y, Su YH, Zhu YG (2014) Impact of reclaimed water irrigation on antibiotic resistance in public parks, Beijing, China. Environ Pollut 184:247-253

Wang XD, Sun C, Gao SX, Wang LS, Han SK (2001) Validation of germination rate and root elongation as indicator to assess phytotoxicity with Cucumis sativus. Chemosphere 44:1711-1721

Wang Y, Wu S, Chen L, Wu C, Yu R, Wang Q, Zhao X (2012) Toxicity assessment of 45 pesticides to the epigeic earthworm Eisenia fetida. Chemosphere 88:484-491

Wilhelm FD (2006) Reactive oxygen species, antioxidants and fish mitochondria. Front Bioscience: J Virt Libr 12:1229-1237

Wollenberger L, Halling-Sørensen B, Kusk KO (2000) Acute and chronic toxicity of veterinary antibiotics to Daphnia magna. Chemosphere 40:723-730

Woo S, Yum S, Kim DW, Park HS (2009) Transcripts level responses in a marine medaka (Oryzias javanicus) exposed to organophosphorus pesticide. Comp Biochem Physiol Part C: Toxicol Pharmacol 149: $427-432$

Xie XJ, Zhou QX, Lin DS, Guo JM, Bao YY (2011) Toxic effect of tetracycline exposure on growth, antioxidative and genetic indices of wheat (Triticum aestivum L.). Environ Sci Pollut Res 18:566-575

Xin J, Huang B, Yang Z, Yuan J, Zhang Y (2013) Comparison of cadmium subcellular distribution in different organs of two water spinach (Ipomoea aquatica Forsk.) cultivars. Plant Soil 372:431-444

Yao H, He Z, Wilson M, Campbell C (2000) Microbial biomass and community structure in a sequence of soils with increasing fertility and changing land use. Microb Ecol 40:223-237

Zhang SH, Gu J, Wang C, Wang PF, Jiao SJ, He ZL, Han B (2015) Characterization of antibiotics and antibiotic resistance genes on an ecological farm system. J Chem 526143:1-8

Zhao L, Dong YH, Wang H (2010) Residues of veterinary antibiotics in manures from feedlot livestock in eight provinces of China. Sci Total Environ 408:1069-1075

Zhou J, Zhu XS, Cai ZH (2010) Tributyltin toxicity in abalone (Haliotis diversicolor supertexta) assessed by antioxidant enzyme activity, metabolic response, and histopathology. J Hazard Mater 183:428-433

Zielezny Y, Groeneweg J, Vereecken H, Tappe W (2006) Impact of sulfadiazine and chlorotetracycline on soil bacterial community structure and respiratory activity. Soil Biol Biochem 38:2372-2380 